\begin{tabular}{|c|c|c|}
\hline & Int.J.Curr.Microbiol.App.Sci (2021) 10(10): 439-443 & \\
\hline & $\begin{array}{l}\text { International Journal of Current Microbiology and Applied Sciences } \\
\text { ISSN: 2319-7706 Volume } \mathbf{1 0} \text { Number } \mathbf{1 0}(\mathbf{2 0 2 1 )} \\
\text { Journal homepage: } \underline{\text { http://www.ijcmas.com }}\end{array}$ & 39 \\
\hline $\begin{array}{l}\text { EXCELLENT } \\
\text { PUBLISHERS }\end{array}$ & & \\
\hline
\end{tabular}

\title{
Quinoa Seed Germination and Vigor Index with Bacterization of Pseudomonas aeruginosa Migula. (PGPR).
}

\author{
Prashanthisandepogu* \\ Department of Botany, TSWRDC (W), Mahendrahills, Hyderabad, India \\ *Corresponding author
}

\begin{tabular}{|l|}
\hline Key w o r d s \\
Pseudomonas \\
aeruginosa. Migula, \\
Plant Growth \\
Promoting \\
Rhizobacteria \\
(PGPR)
\end{tabular}

A B S T R A C T

Pseudomonas aeruginosa Migula is an opportunistic bacteria that lives in soil, water, and even in environments like hot tubs. In present research work studies were conducted on two cultivars of Chenopodium quinoa. Willd was treated with the Strains of Pseudomonas aeruginosa Migula cultured and maintained on nutrient agar medium. Production of the roots and root lets were affected by treatment of PGPR and high number of root lets were reported in 15 days seedlings of Chenopodium quinoa Willd. This Pseudomonas aeruginosa Migula play an important role in soil fertility thus effectively solubilizes fixed phosphorus to exchangeable form and enables solubilization of Phosphorus in soil. Natural Phosphorus solubilization of Pseudomonas aeruginosa Migula improves both plant and soil health and also aids in soil remediation. The population of beneficial Pseudomonas aeruginosa Migula increases the organic content of soil improves soil fertility. Plant Growth Promoting Rhizobacteria (PGPR), plays an important role in improving plant growth. The comprehensive understanding of bacterial plant growth promoting mechanism helps to get sustainable agriculture production under biotic and a biotic stress. PGPR are beneficial for plant growth and also referred as yield increasing bacteria. Treatments with PGPR increases germination percentage, seedling vigor, emergence, plant stand, root and shoot growth, total biomass of the plants, seed weight, early flowering, grains etc., Inoculation of Pseudomonas aeruginosa Migula in agricultural fields improves the uptake of $\mathrm{P}$ and $\mathrm{N}$ in plants with an increase in leaf chlorophyll, total soluble protein and plant biomass production.

\section{Introduction}

Pseudomonas aeruginosa Migula is a bio fertilizer which improves seed germination and crop yield. Pseudomonas aeruginosa have been implicated in the control of several plant pathogens and in promoting plant growth and yield when applied as seed or root inoculants. The effectiveness of bacterial fertilizers depends on their quality, viability and ability to multiply and sustain in rhizosphere. Increased plant growth, yield were reported in cotton and wheat due to treatment of seeds with selected strains of PGPR (Chaitanya 
Kumar Jha and Meenu Saraf, 2015 and Vessey JK 2003) (Guptha et al., 2018) observed significant increase in root growth and nutrient uptake is common in wheat plant. Pseudomonas played a vital role in controlling plant diseases and showed significant effect on plant growth in rice, barley, sorghum and wheat (Avis et al., 2008; Kumar, 2012; Gopalakrishnan et al., 2017). PGPR seed treatment increased seed germination rate and increased emergence root growth, shoot growth, yield, seed weight, leaf area, chlorophyll content and protein content (Adesemoye and Kloepper 2009; Compant et al., 2010). Quinoa is the only food crop that contains all the essential amino acids, trace elements and vitamins, and it is also glutenfree. Inoculation of Quinoa seeds with Pseudomonas aeruginosa under in vitro conditions on MS media was undertaken.

With PGPR, the germination period was reduced, along with a concomitant increase in root and shoot ratio by $76 \%$ and $67 \%$, respectively when compared with noninoculated controls. A decrease in root length and shoot length $(\mathrm{cm})$ indicated dwarfism. However, improvement in number of rootlets and number of branches significantly improved the biomass as well as the strength of both cultivars over the control. In the present work the interaction between the plant growth promoting rhizobacterium Pseudomonas aeruginosa Migula on the growth of Quinoa have been investigated.

\section{Materials and Methods}

Pseudomonas aeruginosa Migula (NCIMB 2036) was selected for growth promotion studies. The bacteria were also tested for its ability to dissolved phosphate.

$P$. aeruginosa Migula was multiplied in mass scale on Glucose nitrate broth and Nutrient agar medium.
Phosphate-solubilizing ability of P.aeruginosa Migula was determined on Pikovskay agar medium (Pikovskaya, 1948) which contains $\mathrm{Ca}_{3} \quad(\mathrm{PO} 4)_{2}$. P.aeruginosa Migula culture grown in Nutrient agar medium for 2 days was streaked on the surface of Pikovskay agar medium plates and incubated for 3 days. The formation of a clear zone surrounding bacterial colonies was considered to be an indicator of positive phosphorus solubilization.

Cells of Pseudomonas grown on modified nutrient agar medium for $48 \mathrm{hrs}$ at $28^{\circ} \mathrm{C}$ to $30^{\circ} \mathrm{C}$ were scraped from the agar surface with a sterile glass rod and mixed thoroughly in Nutrient broth solution surface disinfected dry seeds of Quinoa (10 g each) were dipped in Pseudomonas suspension and then dried overnight and transferred to sterile petridishes under a sterile air steam. The Bacterized seeds were grown under in vitro conditions in culture bottles containing Agar medium and seed germination and post emergence mortality recorded.

\section{Results and Discussion}

\section{Phosphate - Solubilizing Capacity}

The ability of Pseudomonas aeruginosa Migula to dissolve insoluble phosphates was observed by growing bacteria on Pikovskaya's agar medium. Phosphate dissolving ability was recorded quantitatively as zone of discolourization (Fig. 1 and 2).

This test showed the capacity of Pseudomonas aeruginosa ability in dissolving the phosphates. Solubilization zone is $31 \mathrm{~mm}$ in diameter. Plant growth promoting rhizobacterium Pseudomonas aeruginosa (NCIM - 2036) was used in the present work to study the effect of VAM - PGPR interaction on the plant growth. Phosphate solubilizing ability of the bacterium was 
determined and the results revealed that it is capable of dissolving phosphates.

Quinoa seed germination and vigor index with bacterization of Pseudomonas aeruginosa Migula. (PGPR)

Pseudomonas aeruginosa Migula is a bio fertilizer which improves seed germination and crop yield. Inoculation of Quinoa seeds with Pseudomonas aeruginosa under in vitro conditions on MS media was undertaken. With PGPR, the germination period was reduced, along with a concomitant increase in root and shoot ratio by $76 \%$ and $67 \%$, respectively when compared with noninoculated controls. A decrease in root length and shoot length $(\mathrm{cm})$ indicated dwarfism.
However, improvement in number of rootlets and number of branches significantly improved the biomass as well as the strength of both cultivars over the control.

Plant rhizosphere facilitates a great number of beneficial micro organisms such as plant growth promoting rhizobacteria (PGPR).

Utilization of PGPR as a prospective bio fertilizer is one of the practical significance in enhancing crop yields. Fluorescent Pseudmonas bacteria known to produce siderophor compounds, vitamins and growth hormones like Auxins. PGPR can solubizes ionic phosphorus into soluble phosphorus and VAM fungal hyphae mobilizes and provides phosphorus to plants (Fig: 1 and 2).

Fig.1 Pseudomonas aeruginosa on Pikovaskaaya agar medium, showing phosphate solubilization zones. Fig.2 Quinoa seed germination and vigor index with bacterization of Pseudomonas aeruginosa Migula. (PGPR).

Fig.1

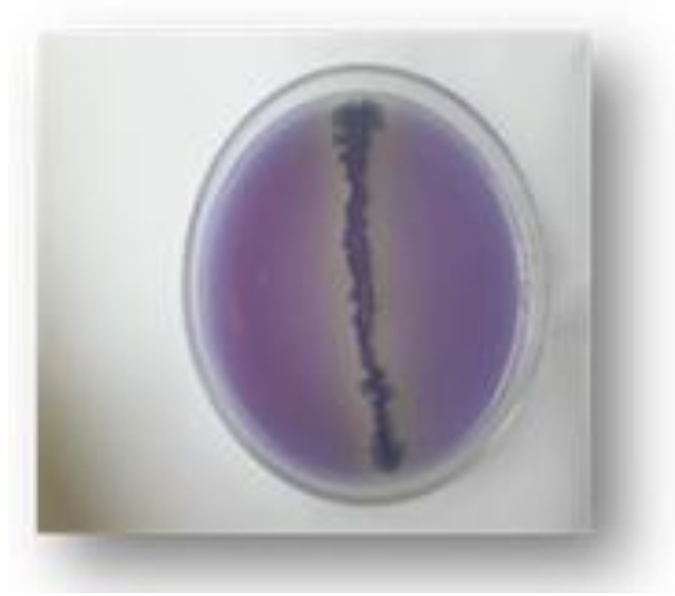

Fig.2 
Fig.3 \& 4 Control (INIA - 431) without PGPR

Fig.5 \& 6 Effect of PGPR on 615 days old plant of INIA - 431

Fig. 7 \& 8 Control (INIA - 427) without PGPR.

Fig.9 \& 10 Effect of PGPR on 15 days old plant of INIA - 427.
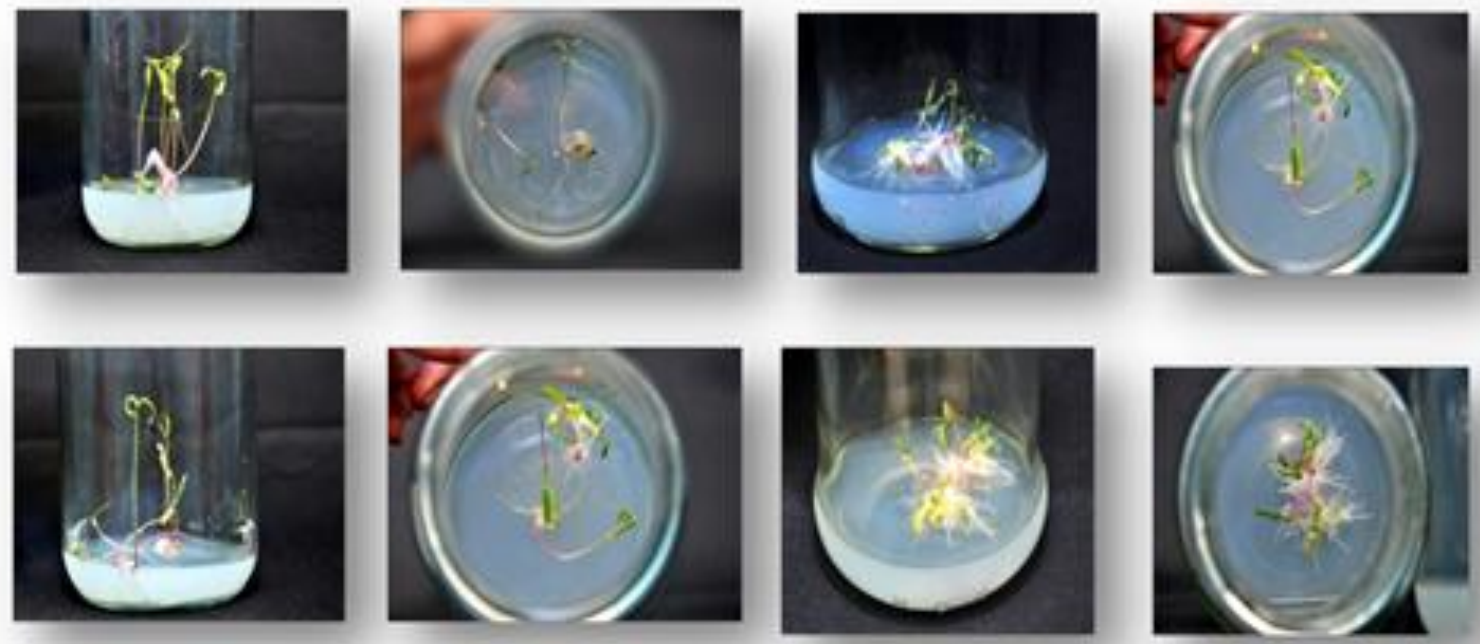

Effect of PGPR on shoot, root formation in two cultivars of Quinoa (Chenopodium quinoa Willd.)

Fig.11 Control.

Fig.12 Effect of PGPR on 15 days old plants of INIA - 431

Fig.13 Control.

Fig.14 Effect of PGPR on 15 days old plants of INIA - 427
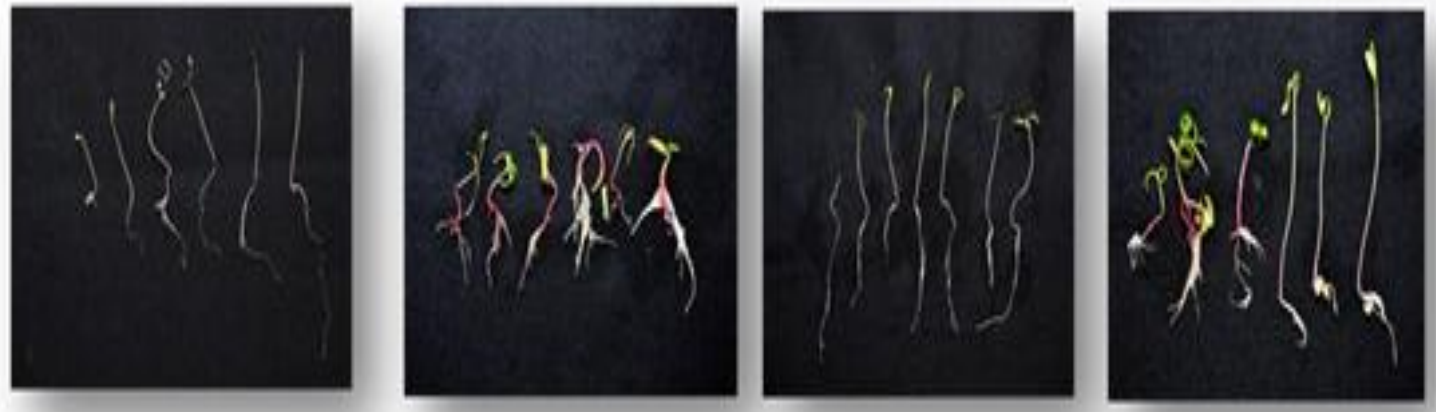

Quinoa (Chenopodium quinoa Willd.) is a high protein content crop which can compensate the rice crop in India. Rhizosphere microflora might stimulate or inhibit the colonization and establishment of introduced bacterial biocontrol agents such as fluorescent pseudomonads. Biocontrol agent might also stimulate mycorrhizal infection and reduces the utilization of chemical fertilizers as demonstrated by (Adesemoye et al., 2009) 
(Singh et al., 2011) reported that PGPR increases the uptake of $\mathrm{N}$ and $\mathrm{P}$ plays a vital role as Biofertilizer alone and these bacteria referred as mycorhization helper bacteria (MHB), MHB showed better growth of Quinoa plant when the two cultivars treated with Specific strains of Pseudomonas and have been shown increase in the root growth and increased the number of rootlets in 15days plants of Quinoa in both the cultivars (INIA431 and INIA - 427) (Fig:3 to 14) thus PGPR improves the uptake of the N,P,K, shoot growth and yield of some agricultural crops (Joseph et al., 2007).

\section{Acknowledgement}

I cannot express my enough thanks to my guide Prof. M. Mamatha for her continued support and guidance to complete my research work. My completion of this research work could not be accomplished without support of Biotechnology Department, Telangana University.

\section{References}

Adesemove, A., H. Torbert J. Klopper, Plant Growth Promoting Rhizobacteria Allow Reduced application rates of chemical fertilizers, DOI: 10.1007/soo248-009-9531y. Corpus ID: 8789559.

Adesemoye A O, Kloepper J W (2009) Plantmicrobes interactions in enhanced fertilizer use efficiency. Appl Microbiol Biotechnol 85:1-12.

Avis $\mathrm{T} \mathrm{J}$, Gravel V, Antoun $\mathrm{H}$, Tweddell R J (2008) Multifaceted beneficial effects of rhizosphere microorganisms on plant health and productivity. Soil Biol Biochem 40:1733-1740.
Chaitanya Kumar Jha and Meenu Saraf, Plant growth promoting Rhizobacteria (PGPR): a review, E3 Journal of Agricultural Research and Development Vol. 5(2). pp. 0108-0119, April, 2015 Available online http://www.e3journals.org ISSN: 2276-9897 (c) E3 Journals 2015.

Compant S, Clément C, Sessitsch A (2010) Plant growth promoting bacteria in the rhizo-and endosphere of plants: their role, colonization, mechanisms involved and prospects for utilization. Soil Biol Biochem 42(5):669-678.

Gopalakrishnan S, Vadlamudi S, Samineni S (2017) Nitrogen fixation, plant growth and yield enhancements by diazotrophic growthpromoting bacteria in two cultivars of chickpea (Cicer arietinum L.). Biocatal Agric Biotechnol 11:116-123.

Govind Gupta, Shailendra Singh Parihar, Narendra Kumar Ahirwar, Sunil Kumar Snehi and Vinod Singh*: Plant Growth Promoting Rhizobacteria (PGPR): Current and Future Prospects for Development of Sustainable Agriculture, J Microb Biochem Technol 2015, 7:2.

Joseph B, Patra R R, Lawrence R (2007) Characterization of plant growth promoting Rhizobacteria associated with chickpea (Cicer arietinum L). Int $\mathrm{J}$ Plant Prod 1(2):141-152.

Kumar et.al. 2012, Influence of plant growth promoting rhizobacteria (PGPR) on the growth of chickpea (Cicer arietinum L.), Annals food science and Technology.

Singh, J. S., V. C. Pandey and D. P. Singh. 2011. Efficient soil microorganisms: A new dimension for sustainable agriculture and environmental development. Agri. Eco. Environ., 140: 339-353.

Vessey J K (2003). Plant growth-promoting rhizobacteria as biofertilizers. Plant Soil 255:571-586.

\section{How to cite this article:}

Prashanthisandepogu. 2021. Quinoa Seed Germination and Vigor Index with Bacterization of Pseudomonas aeruginosa Migula. (PGPR). Int.J.Curr.Microbiol.App.Sci. 10(10): 439-443. doi: https://doi.org/10.20546/ijcmas.2021.1010.052 